\title{
El tema del mal en "Poemas Humanos" de César Vallejo
}

POR JAMES HIGGINS

Poemas humanos de César Vallejo es un libro dominado por una convicción de to absurdo de las existencia. Uno de los temas principales es el mal, cuya presencia inexplicable en el universo constituye tuna de las grandes manifestaciones de lo absurdo. Es de notar que Vallejo tiende a identificar el mal con el dolor, a tal punto que los dos se confunden; pero es evidente que son dos cosas distintas: el mal es la causa del sufrimiento y el sufrimiento efecto del mal.

En algunos casos Vallejo atribuye el sufrimiento a la mala organización de la estructura social. Este importante tema es demasiado extenso para incluir en este trabajo y merece un estudig aparte. Simplemente, por ahora, quiero señalar la presencia del mal en la obra de Vallejo.

Además, en la poesía de Vallejo, no todo el mal se explica por factores sociales o materiales. Fundamentalmente Vallejo atribuye el sufrimiento a las condiciones de la vida misma. El $\mathrm{mal}$ es inherente a la vida y vivir es sufrir. El poeta niega enfáticamente que la vida sea buena, contrariamente, afirma que es una fuente de angustia: 
"Y no! No! No! Qué ardid, ni paramento!

Congoja, sí, con sí firme y frenético...

congoja, si, con toda la bragueta" ${ }^{(1)}$.

Después de evocar su sufrimiento, observa:

"Así es la vida, tal

como es la vida... (137)

Sufre porque vive y la vida es una aflicción irremediable. En Dos niños anhelantes Vallejo examina posibles causas del sufrimiento humano y las rechaza una por una. Afirma que es la vida misma la que hace sufrir al hombre:

"Es la vida no más; sólo la vida". (88)

Para vallejo el mal está identificado con la vida. En parte esto significa que el mal está arraigado en la naturaleza humana. El hombre va por la vida "alzando al mal en brazos" (29): no puede escapar del mal porque lo lleva consigo. Su vida es un "juego de crímenes" (56), porque es un criminal que perpetra barbaridades contra sus semejantes. Es incapaz de actuar sin herir a los demás. Hasta el amor causa dolor puesto que pone a los hijos en un mundo donde tienen que sufrir. Por eso Trilce $L V I$ describe a los padres como:

$$
\begin{aligned}
& \text { "... ellos dues como Dios de tanto amor } \\
& \text { se comprendieron hasta creadores } \\
& \text { y nos quisieron hasta hacernos dano" } \left.{ }^{2}\right)
\end{aligned}
$$

Por lo tanto la existencia plantea un grave problema moral: ¿cómo comportarnos para evitar herir a los otros? Así Vallejo pregunta:

"Cómo ser

y estar, sin darle cólcra al vecino?" (130)

En otro poema afirma:

" $Y$ se debe todo a todos". (138).

Todos los hombres tenemos una responsabilidad por ei sufrimiento que hay en el universo. Para Vallejo el mal es in-

1. César Vallejo, Poemas humanos, Ed. Perú Nuevo, Lima, 1961, p. 36. Todas las referen-

2. Césa: Valleio, Trilce, Ed. Perú Nuevo, Lima, 1961, p. 94. 
herente a la vida, sobre todo, en el sentido de que existe en el universo una fuerza malévola que desde los principios del tiempo se ha complacido en hacer sufrir a los hombres y en convertir la vida en sufrimiento. Este concepto del mal es el más frecuente en la poesia de Vallejo y es propiamente el tema de este trabajo.

A veces la visión que tiene Vallejo de la fuerza del mal es muy parecida a la de los poetas románticos: el mal persigue al hombre implacablemente, asestándole golpes de desguacia. Es significativo que sea éste el tema del poema liminar de su primer libro de poesías, Los Heraldos Negros, porque las fuerzas oscuras del mal se ciernen sobre toda su obra. El poema comienza con una afirmación de la existencia de tales golpes:
"Hay golpes en la vida, tan fuertes... Yo no sé! Golpes como del odio de Dios; como si ante ellos, la resaca de todo lo sufrido se empozara en el alma... Yo no sé!"'( $\left.{ }^{3}\right)$.

El poeta se encuentra frente a algo hostil, sin poder comprender ni explicar ni siquiera describir estos golpes. Lo más que puede hacer es ofrecer una serie de aproximaciones: es como si Dios, con toda su omnipotencia, se hubiera vuelto contra el hombre y volcado su odio sobre él; es como si todo el sufrimiento del pasado hubiera irrumpido en el presente. Hacia el final del poema, Vallejo abanadona el intento de describir y explicar y se limita a retratainal hombre.sPreso del terror, mira por sobre el hombro, como un criminal culpable, esperando que caiga el golpe siguiente:

" $Y$ el hombre... Pobre... Pobre! Vuelve los ojos, (como cuando por sobre el hombro nos llama una palmada; vuelve los ojos locos, y todo lo vivido se empoza, como un charco de culpa, en la mirada".

En el curso del poema no hay ninguna progresión. El último verso repite el primero, de manera que el poema completa un círculo y el sufrimiento se presenta como un círculo vicioso sin salida:

"Hay golpes en la vida, tan fuertes... Yo no sé!"

3. César Vallejo, Los Heraldos Negros, Ed. Perú Nuevo. Lima, 1961, p. 17 
El poena termina, como ha empezado, con la afirmación de la existencia de los golpes y de la incapacidad del poeta para entenderlos. El poeta no comprende estos golpes, pero es evidente que suponen la existencia de alguna fuerza del mal.

Al cavilar en la vida... (30) nos ofrece la imagen de un clavo fraguado en sufrimiento y lanzado sobre la tierra desde el cielo:

"envuelto en trapos blancos cae,
cae planetariamente,
el clavo hervido en pesadumbre; cae!"

El clavo está envuelto en trapos blancos, lo cual da a entender que estos golpes son a menudo insidiosos y no siempre evidentes. En estos versos la técnica poética refuerza admirablemente el sentido de las palabras para crear la senšación de un clavo que cae inexorablemente hacia la tierra. Se insiste en el verbo caer mediante una triple repetición y el sujeto del verbo es diferido hasta el tercer verso. El primer verbo, puesto de relieve al final de verso, es recogido por el segundo verso donde el sentido y la sonoridad del adverbio le otorgan una dimensión universal. El tercer verso, destacado también al final el verso, resuena como un batacazo sordo, señalando que nada ha podido impedir el golpe. ción:

Uno de estos golpes constituye - ef tema de otra composi-

"Hoy le ha entrado una astilla.

Hoy le ha entrado una astilla cerca, dándole cerca, fuerte, en su modo

de ser y en su centavo ya famoso." (85).

El poema empieza con un simple informe: la pobre scñora ha sufrido una terrible desgracia. La imagen de la astilla que le penetra y la sencillez de las palabras, desnudas de toda retórica, expresan toda la agonía del golpe. Al insistir en el adverbio "hoy", el poeta destaca que esto es algo que está pasando en este momento y no algo remoto. El segundo verso repite la constatación inicial y la elabora: el golpe le ha dado de cerca, con toda fuerza, haciendo doler todo su ser.

Frente al dolor de la señora el poeta pronuncia una expresión convencional de condolencia: el destino le ha sido cruel, ha sufrido mucho: 


\section{"Le ha dolido la suerte mucho, todo; \\ le ha dolido la puerta, \\ le ha dolido la faja..."}

En seguida corrige el convencionalismo: no sólo ha sufrido mucho, ha sufrido totalmente. El sufrimiento no se siente de una manera parcial sino que destroza todo el ser y convierte todo en una fuente de sufrimiento. Así hasta objetos inanimados como la puerta y su ropa le causan dolor a la pobre señora.

El mal parece algo lejano que no nos afecta, pero en la segunda estrofa Vallejo señala que esta lejanía es ilusoria:

"La inmensidad persíguela

a distancia superficial, a un vasto eslabonazo."

El mal es inmenso y anónimo - el sustantivo abstracto "inmensidad" expresa lo difuso que es -, persigue a la pobre señora, la acecha esperando una oportunidad para precipitarse sobre ella, y la alcanza de un solo tranco enorme. señora:

A continuación Vallejo explica el significado de la pobre

"Hoy le entró a la pobre vecina de viaje

una llama apagada en el oráeuto;

hoy le ha entradociunal iastillae"rso"

El primer verso del poema se repite obsesivamente a través de la comoposición como una letanía del mal, una reite. ración de la desgracia de la señora. La experiencia del sufrimiento ha extinguido en ella toda esperanza y toda fe, ha apagado la llama del oráculo. Pero la suya no es una experiencia aislada: es nuestra compañera en el viaje por la vida y su suerte puede ser la suerte de todos.

En la última estrofa el poeta recurre a la reiteración para expresar todo el dolor que le ha sido infligido a la señora:

"Le ha dolido el dolor, el dolor joven,
el dolor niño, el dolorazo..."

Enumera una serie de palabras de la misma familia, lo cual da la sensación de que el dolor es una plaga de sabandi- 
jas que constantemente se están multiplicando. La enumeración la remata con el aumentativo "dolorazo" que expresa la enormidad y la fuerza de su sufrimiento. Aquí nuevamente el sufrimiento implica la presencia de una fuerza malévola que inflige el dolor. El poema termina con una expresión de condolencia, lo único que puede ofrecer el poeta, impotente frente al mal:

\section{"La pobre pobrecita!"}

Otra vez Vallejo tiene que recurrir a la reiteración para expresar la compasión que siente.

En los poemas que acabamos de examinar el mal se presenta como una fuerza que lanza golpes contra el hombre. En otras ocasiones Vallejo tiene una visión del mal que nos hace pensar en las novelas de Kafka: la vida es una especie de pesadilla, llena de horror, en que el hombre es perseguido por un mal que no comprende. Va corriendo, andante (29) indica que la condición del hombre es la huida. La estructura del poema crea la sensación de una huida frenética: se basa en versos entrecortados, en el encabalgamiento, y en la repetición del verbo "huir" con los verbos vecinos "ir", "correr" y "andar". El primer verso junta estos cuatro verbos de movimiento:

\section{"Va corriendo,tandante, huyendos de sus pies.}

El gerundio "huyendo", colocado al final del verso, requiere a la vez una pausa y un encabalgamiento de manera que se insiste en la idea de la huida al mismo tiempo que estamos precipitados al verso siguiente. El segundo verso, donde el símbolo de los pies - los pies, instrumentos de huida, se convierten en símbolos de huida - ocupa casi todo el verso y queda así destacado, ofrece una forma de reiteración que consiste en llevar un concepto más allá de sus propios límites al aplicar el concepto a sí mismo: el hombre huye de su condición de siempre estar huyendo.

Después de una breve pausa señalada por los puntos suspensivos la huida continúa:

"Va con dos nubes en su nube, sentado apócrifo, en la mano insertos sus tristes paras, sus entonces fúnebres." 
Tenemos una reiteración en forma de juego de palabras. La nube es símbolo del destino, de la fatalidad que persigue al hombre. Pero su nube consiste de dos nubes: es como si le persiguieran dos destinos. La paradoja "Va...sentado" es explicada por el adjetivo "apócrifo": el hombre siempre se está esforzando por escapar del mal hasta cuando aparenta estar en descanso. En estos versos Vallejo cambia la función gramatical de las palabras, empleando una preposición (para) $\mathrm{y}$ un adverbio (entonces) como sustantivos. La función de "para" es indicar el destino de algo y por lo tanto representa el futuro que le espera al hombre; es reiterada por "entonces", que también se refiere al futuro. Estas expresiones son calificadas por adjetivos que son sinónimos y que reiteran que el futuro del hombre seguirá el mismo patrón de miseria y de sufrimiento que el presente. Por que el hombre lleva su futuro en sus manos: no puede escapar del mal porque es algo que lleva consigo, algo inherente en él y en la vida.

La segunda estrofa empieza con otro verbo de movimiento y nos precipita otra vez en la huida:

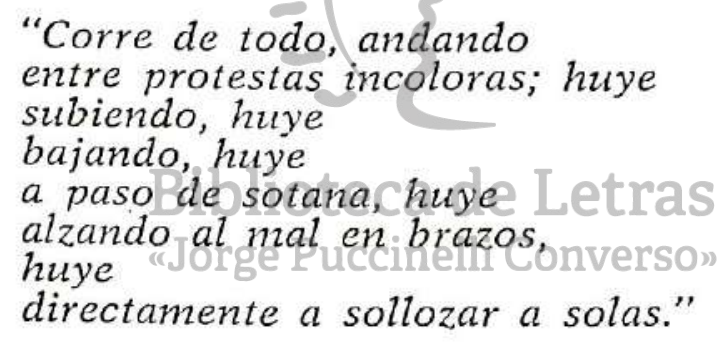

Toda la estrofa da una impresión de movimiento. El gerundio "andando" es otro ejemplo de un verbo de movimiento puesto de relieve al final de verso y otro ejemplo de pausa y encabalgamiento simultáneos, de manera que se subraya la idea de movimiento al mismo tiempo que estamos lanzados al verso siguiente. Este es también el caso de "huye" que se coloca al final de cuatro versos y ocupa todo el penúltimo verso. Además se insiste en el verbo "huir", la palabra clave del poema. Este verbo reaparece once veces en el curso del poema como el tema central de una composición musical, mientras que los verbos vecinos "ir" y "correr" se repiten tres veces y "andar" dos veces. También la estrofa consiste de una serie de versos cortos que en realidad constituyen un solo movimiento: desde el segundo al penúltimo verso hay un solo movimiento ininterrumpido. 
Puesto que el mal es inherente a la vida, todo en la vida le inspira terror al hombre y todo le hace huir. Protesta contra la injusticia del sufrimiento pero, puesto que sus protestas son inútiles, se desanima y sus protestas se vuelven insipidas y $\sin$ fuerza. La antítesis, "subiendo...bajando", subraya la noción de una huida constante. Pero también señala lo frenética e inútil que es esta huida: el hombre huye en una dirección pero, al encontrarse de nuevo frente al mal, vuelve sobre sus pasos para huir en la dirección contraria. Los dos versos siguientes ofrecen la imagen de una procesión religiosa $\left({ }^{4}\right)$. El hombre es como un sacerdote que lleva una imagen en una procesión, pero la imagen que lleva es el mal: la vida del hombre es un homenaje al mal que rige la existencia. El último verso de la estrofa nos dice cuál es el término de la huida: por donde corra el hombre siempre llega al mismo destino, el sufrimiento en la soledad. Este es quizá el aspecto más terrible del sufrimiento humano: el aislamiento, la sensación de estar desolidarizado de los demás hombres. Es de notar que la aliteración "sollozar a solas" refuerza acústicamente la idea de llanto, mientras que el adverbio "directamente", por su sentido, su sonoridad y su longitud, contribuye a la sensación de que el hombre va siempre en línea recta hacia el mismo destino.

La tercera estrofa proyecta la huida hacia el futuro:

"Adonde ivaya,

lejos de sus fragosos, cáusticos falones,

lejos deloaire, lejos de su viaje,so"

a fin de huir, huir y huir y huir

de sus pies - hombre en dos pies, parado

de tanto huir - habrá sed de correr."

Los primeros versos enumeran tres imágenes de huida: "talones", "aire" y "viaje". Esta es la condición permanente del hombre: es un caminante expuesto a los elementos y que siempre está de viaje. El adjetivo "cáustico" sugiere que los pies arden y hacen correr, mientras que "fragoso" da una idea de pesadez: el hombre quiere correr rápido pero sus pies quedan intrincados. Así los dos adjetivos se oponen para subrayar el tema central del poema: el hombre huye del mal pero nunca logra escapar. En estos primeros versos Vallejo reitera también la proposición "lejos" para insistir en que el anhelo constante del hombre es alejarse de su condición de siempre

4. Es posible interpretar estos versos en otro sentido: el hombre no puede escapar del mal: como un sacerdote que intenta correr con sotana, sus pies quedan intrincados; $y$ no puede escapar porque lo lleva consigo, es inherente a él y a la vida. 
estar huyendo. En el cuarto verso el verbo "huir" reaparece y se repite cuatro veces: se insiste en la palabra a tal punto que se convierte en una especie de fatalidad que se cierne sobre el hombre. El hombre está condonado a estar siempre en dos pies, corriendo, sin poder nunca descansar. Pero al mismo tiempo se da la paradoja de que, puesto que esta huida es inútil, puesto que el hombre nunca alcanza un refugio para cubrirse del mal, es como si estuvicra parado, inmóvil. Por mucho que corra y por donde vaya el hombre nunca llegará a escapar del mal y siempre tendrá que seguir huyendo. Es significativo el empleo del verbo "haber" en vez de "tener": el instinto de huir del mal es algo impersonal, exterior al individuo; es una ley de la naturaleza común a todos los hombres de todas las épocas; es una ley de la vida misma.

La última estrofa, basada en una serie de negaciones, excluye la posibilidad de un refugio del mal:

$$
\begin{aligned}
& \text { "Nada, sino sus pies, } \\
& \text { nada sino su breve calofrio, } \\
& \text { sus paras vivos, sus entonces vivos..." }
\end{aligned}
$$

Para el hombre no hay refugio del mal: la única realidad es su huida, simbolizada por los pies. Para él la vida no es sino un calofrío, el terror inatenuado, pero es un terror que en la historia del universo sólo es un breve momento sin mayor importancia. El último verso del poema señala que el futuro que le espera al hombrees vivo.e Elosufrimiento del futuro él lo está viviendo ahora porque el futuro sólo repetirá el presente y porque el terror del sufrimiento futuro se acumula en el presente. Este último verso recoge el último verso de la primera estrofa, de manera que el pocma completa un círculo: como en Los Heraldos Negros el sufrimiento se presenta como un círculo vicioso del cual no se puede salir. Además el poema termina con puntos suspensivos: no concluye sino que abre sobre un futuro en que el mal seguirá acosando al hombre.

Este mismo ambicnte de horror y de pesadilla se encuentra en El acento me pende...(63). El punto de partida es un ruido ominoso que le inspira terror al poeta:

\footnotetext{
"El acento me pende del zapato; le oigo perfectamente sucumbir, lucir, doblarse en forma de ámbar y colgar, colorante, mala sombra."
} 
No puede liberarse de este ruido amenazador que le sigue como una bola encadenada a su pie. El ruido cambia de tono - a veces suena fuerte, a veces bajo, otras veces atenuado - y difunde un aire de mal augurio. El poeta siente que algo le amenaza. Tiene la sensación de ser demasiado grande y demasiado expuesto y quisiera encogerse para desaparecer de vista:

"Me sobra así el tamaño,

me ven jueces desde un árbol.

me ven con sus espaldas ir de frente,

entrar a mi martillo,

pararme a ver a una niña

$y$, al pie de un urinario, alzar los hombros."

Tiene una sensación terrible de ser juzgado: los pájaros posados en las ramas de los árboles le parecen la encarnación de jueces inhumanos que le vigilan, esperando el momento de condenarle. De estos jueces inexorables no puede esperar ninguna misericordia: le dan la espalda y miran impasivos mientras tropieza con la desventura. Le observan hasta en los detalles más intimos: cuando mira a una chica y cuando orina. Esta estrofa nos hace pensar en El Proceso de Kafka donde el protagonista es prendido, juzgado y condenado sin saber siquiera cuál es su crimen. El poeta se siente amenazado por un poder implacable e incógnito del cual teme ser víctima.

En los versos siguientes encontramos al poeta solo frente a esta potencia hostil. Se siente abandonado por los demás hombres que se niegan a ayudarle. Pero en medio de su abandono reacciona con orgullo, afirmando que es fuerte y no necesita ayuda:

"Seguramente nadie está a mi lado, me importa poco, no lo necesito."

Sin embargo, en los últimos versos del poema esta confianza queda destrozada:

"Imperturbable! Imperturbable! Suenan

luego, después, fatídicos teléfonos. Es el acento; es él."

La exclamación repetida expresa una seguridad algo forzada que no tarda en esfumarse al volver a manifestarse el ruido ominoso. Este ruido, semejante al zumbido de hilos te- 
lefónicos y que el lector también ove mediante una onomatopeya, parece señalar la presencia de alguna fuerza malévola y en el último verso el poeta, solo e indefenso, lanza un grito de horror al sentir esta fuerza avanzar sobre él.

A veces Vallejo ve el mal como una fuerza que lanza golpes contra el hombre, a veces como una fuerza oscura que le persigue como en una pesadilla. Los nueve monstruos (57) nos ofrece una visión del mal parecida a la de Camus en La Peste: el mal es una plaga que se adueña del universo. Es de señalar que en esta composición Vallejo habla del dolor más que del mal, pero es evidente que el dolor supone la existencia de una fuerza del mal que hace sufrir porque en el curso del poema el poeta confunde el mal con el dolor. El poema es una llamada que hace el poeta a la humanidad, anunciándole una gran catastrofe:

$$
\begin{aligned}
& \text { " } Y \text {, desgraciadamente, } \\
& \text { el dolor crece en el mundo a cada rato, } \\
& \text { crece a treinta minutos por segundo, paso a paso." }
\end{aligned}
$$

La conjunción "y", más que iniciar el poema, nos introduce en el curso de una meditación obsesiva sobre el dolor que ha empezado mucho antes, mientras que el adverbio, explotado por su valor sonoro, da el tono grave y angustiado que caracteriza toda la composición. El sustantivo "dolor", puesto de relieve al principio del segundo verso, anuncia el tema del poema: el dolor, un dolor immenso que infesta todo el universo sin dejar inmune un solo rincón un dolor que se propaga constantemente. Todo el poema está construido alrededor de esta palabra que reaparece de una manera obsesionante, como el tema central de una composición musical. Se repite once "veces, sin contar palabras vecinas como "doler", "doloroso", "desdicha", "mal", "sufrimiento", "sufrir". El tercer verso recoge el verbo "crecer" e insiste' en él: el dolor no sólo se propaga sino que se propaga con una velocidad inconcebible para el hombre, una velocidad mil ochocicntas veces más rápida que el paso del tiempo.

El cuarto verso reitera los dos anteriores y define la esencia del dolor: su fertilidad asombrosa. El dolor engendra más dolor; mientras pensamos en lo que es el dolor ya se ha du-
plicado:

"y la naturaleza del dolor, es el dolor dos veces y la condición del martirio, carnivora, voraz, es el dolor, dos veces 


\section{y la función de la yerba purísima, el dolor dos veces $y$ el bien de ser, dolernos doblemente".}

El resto de la primera estrofa sigue una misma fórmula, "y... dos veces", con una variante en el último verso, lo cual da al poema un tono de letanía. Pero se trata sobre todo de una reiteración: cada repetición de la fórmula no hace sino elaborar e insistir en la afirmación inicial de que el dolor se duplica. Puesto que la vida es sufrir la condición del hombre es la del mártir, con la diferencia de que éste sufre por una causa mientras que el hombre sufre sin causa. El dolor, o más exactamente el mal, es un monstruo hambriento que vive del hombre, y a medida que le devora crece, y a medida que crece su apetito se vuelve cada vez más insaciable. El mal se manifiesta en todo y todo le hace sufrir al hombre. Así la función de la yerba es hacer doler al hombre pero es inocente (purísima) puesto que no es sino un agente inconsciente del sufrimiento y no la causa. La paradoja, "bien... dolernos", corresponde a una contradicción de la vida misma: el mayor bien del hombre es la vida pero este bien es también su mayor desgracia puesto que vivir es sufrir. Estos versos reiteran que la condición del hombre es sufrir una agonía que se hace cada vez peor.

La segunda estrofa se basa en la repetición de una misma fórmula gramaticăl consiste de una serie de frases introducidas por el adverbio "jamás". Esto da una unidad a la estrófa y un tono der letanía, peroi eso sobres todo otro caso de reiteración. Cada elemento de la estrofa ilustra o elabora la misma idea general: la condición humana nunca ha sido tan crítica como ahora. El primer adverbio introduce una serie de sustantivos que no tienen ninguna relación entre sí:

"Jamás, hombres humanos, hubo tanto dolor en el pecho, en la solapa, en la car. en el vaso, en la carniceria, en la aritmética!" tera,

He aquí un ejemplo de enumeración caótica la cual ha sido señalada por Spitzer como una de las características de la poesía moderna. En el caso de Vallejo sería más exacto llamarla enumeración reiterativa, porque cada elemento reitera que todo le hace sufrir al hombre.

Una segunda serie de frases introducidas por "jamás" 
nos pone frente a algunas paradojas que señalan que el mal se manifiesta de la maneras menos esperadas:

$$
\begin{aligned}
& \text { "Jamás tanto cariño doloroso, } \\
& \text { jamás tan cerca ariemetió lo lejos, } \\
& \text { jamás el fuego nunca } \\
& \text { jugó mejor su rol de frio muerto!" }
\end{aligned}
$$

El dolor está presente hasta en el amor, porque sufrimos debido a que sufren aquellos que amamos, y porque somos incapaces de amar sin herir o ser heridos. La idea de distancias pierde sentido frente al mal, porque el mal, como Dios, está en todas partes, en todo momento. El hombre nunca está al abrigo del mal, ya que es capaz de asestar golpes en varios sitios a la vez, cerca y lejos. El fuego, puesto que mata, contiene dentro de sí el frío de la muerte:

Otra oración de este tipo ofrece dos juegos de palabras:

$$
\begin{aligned}
& \text { "Jamás, señor ministro de salud, fue la salud.. } \\
& \text { más mortal } \\
& \text { y la migraña extrajo tanta frente de la frente!". }
\end{aligned}
$$

El primero expresa la universalidad del dolor: en general identificamos el dolor con la enfermedad y el bienestar con la salud, pero Vallejo hace ver que la salud no nos exime del sufrimiento porque no todo sufrimiento es físico. La invocación al señor ministro es irónica: el ministro es la autoridad pública responsable de la salud y del bienestar de la, población, pero el contexto indica que todo el aparato político - administrativo de la sociedad es impotente para impedir que los hombres sufran. El segundo juego de palabras procede. del empleo de la palabra "frente" en dos sentidos diferentes. En el segundo caso tiene su sentido literal, pero en el primero su sentido es figurado: lleva asociaciones de sudor de la frente y de introspección atormentada, y por lo tanto, significa "dolor". A este juego de palabras se junta una reiteración: "migraña" es un galicismo que significa dolor de cabeza, de manera que el verso quiere decir que jamás el dolor de cabeza sacó tanto dolor de la cabeza.

En la tercera estrofa reaparece el verbo "crecer" con el cual se había iniciadio el poema. Pero ahora tiene un significado adicional. En la estrofa anterior el poeta ha afirmado que la condición humana nunca ha sido tan crítica, pero ahora el verbo "crecer" nos proyecta en un futuro cada vez más crítico a medida que se propaga el mal: 
"Crece la desdicha, hermanos hombres,

crece el mal por razones que ignoramos

$y$ es una inundación con propios liquidos, con propio barro y propia nube sólida!"

Estos versos revelan claramente que Vallejo confunde dolor y mal. Como Camus, ve el mal como una catástrofe que devasta el universo. Para él es una inundación, pero no depende de factores exteriores como la lluvia, sino que contiene dentro de sí los medios para propagarse.

La estrofa termina con otro ejemplo de enumeración caótica o reiterativa:
"y esta oreja da nueve campanadas a la hora
del rayo, y nueve carcajadas
a la hora del trigo, $y$ nueve sones hembras
a la hora del llanto, y nueve cánticos
a la hora del hambre, y nueve truenos
y nueve látigos, menos un grito."

Vallejo enumera las desgracias naturales que le caen al hombre. Los látigos son los males con los cuales la naturaleza le castiga. El rayo y los truenos son ejemplos de la furia y la violencia que la naturaleza desencadena contra él. El trigo es símbolo del trabajo y del sudor que la naturaleza le exige para sustentarse. El hambre es la aflicción que sufre cuando la naturaleza se burla de sus esfuerzos. Todos estos males se resumen en el llanto, el sufrimiento pasivo de una humanidad fustigada por la naturaleza. El poeta enumera también las respuestas del hombre a estos males. Dobla campanas por sus muertos; entona himnos de súplica; ríe a carcajadas de desesperación; emite lamentaciones. Su actitud se caracteriza por su pasividad: su llanto es identificado con las mujeres, esencialmente pasivas, y sus cánticos, por la asociación religiosa, suponen una aceptación resignada de la desgracia. Lo que falta a sus lamentaciones es el grito de protesta, de rebelión contra la injusticia del sufrimiento humano.

En estos versos la reiteración del número nueve parece aclarar el título del poema. Los nueve monstruos no son mencionados en la composición, pero parece que son dioses misteriosos y malévolos que rigen el universo y difunden el mal, castigando al hombre con nueve truenos y nueve látigos y provocando en él nueve lamentaciones. Los nueve monstruos son, por lo tanto, el espíritu del mal. 
La cuarta estrofa recoge la palabra "dolor" y elabora el tema del sufrimiento universal:

$$
\begin{aligned}
& \text { "El dolor nos agarra, hermanos hombres, } \\
& \text { por detris, de perfil, } \\
& \text { y nos aloca en los cinemas, } \\
& \text { nos clava en los gramónonos, } \\
& \text { nos desclava en los lechos, cae perpendicularmente } \\
& \text { a nuestros boletos, a nuestras cartas." }
\end{aligned}
$$

Es de subrayar que para Vallejo el dolor no es una abstracción sino una realidad viva. Casi lo personifica: es un monstruo que acosa al hombre por todos lados y cuya enorme mano alcanza los sitios más recónditos. Y se siente como un clolor físico, real y tangible, que nos trastorna y nos penctra como un clavo. En estos versos Vallejo recurre otra vez a una enumeración reiterativa para dar la impresión de un mal que ataca al hombre en todo lo que hace o toca. Los sustantivos "cinemas", "gramófonos" y "lechos" tienen en co. mún que son sitios o instrumentos de recreo o de descanso. En este contexto resulta evidente que el hombre no puede encontrar diversión ni descanso por el sufrimiento. Aun en el momento de descanso, en el lecho, sufrimos. El dolor no nos permite descansar, nos desclava en el sentido de que nos extrae del descanso. El mal cae sobre el hombre como un rayo del cielo y le ataca en todo lo que toca. El adverbio, por su sentido y su sonoridad, refuerza la noción de un rayo que cae implacablemente en línea recta hacia su blanco, mientras que al final del verso hay a la vezluna pausa, que subraya la idea de una caída, y un encabalgamiento que crea una impresión

A continuación Vallejo emplea la técnica de explotar todas las variantes posibles de una fórmula para enumerar los efectos diferentes que produce el sufrimiento en los hombres:

"Pues de resultas

del dolor, hay algunos

que nacen, otros crecen, otros mueren, $y$ otros que nacen $y$ no mueren $y$ otros

que sin haber nacido, mueren, y otros que no nacen ni mueren (Son los más)."

Unos nacen a la realidad de la vida, se dan cuenta de que el mundo es absurdo y la vida sin sentido. Otros crecen en estatura moral por la dignidad con que arrostran el sufrimiento. Otros mueren, son derrotados moralmente por el su- 
frimiento. Otros nacen a la realidad de la vida, pero sin dejarse vencer por el absurdo. Otros quedan postrados por el sufrimiento sin darse cuenta de que la vida es absurda. La mayoría de los hombres viven y sufren de una manera superficial, inconsciente, mecánica, sin darse cuenta del absurdo de la vida y sin que el sufrimiento les afecte profundamente.

En la última estrofa, después de haber evocado un mundo en que todo sufre, el poeta dice que no puede aguantar más este estado de cosas:

"Cómo, hermanos humanos, no deciros que ya no puedo y ya no puedo con tanto cajón, tanto minuto, tanta lagartija y tanta inversión, tanto lejos y tanta sed de sed!"

Estos versos tienen toda la tensión de una situación insoportable. La tensión se nota en la necesidad que siente el poeta de formular su incapacidad para aguantar más, en la repetición de "ya no puedo", en la reiteración de "tanto", y en la enumeración reiterativa. Esta es una enumeración que recoge los varios hilos del poema y así resume todo lo anterior. Remata el poeta con una forma de reiteración que ya hemos señalado en otro poema y que consiste en aplicar un concepto a sí mismo: "sed de sed". El hombre tiene sed, o esperanza de una vida mejor, pero ha sufrido tanto que ha perdido la esperanza y no aspira sino a recuperarla.

En medio de esta angustia el poeta pregunta qué se debe hacer. La pregunta va dirigida al Ministro de Salud:

"Señor Ministro de Salud: qué hacer? Ah! desgraciadamente, hombres humanos, hay, hermanos ,muchisimo que hacer."

No recibe contestación -como antes, la inferencia es que la sociedad es incapaz de solucionar el problema- y el poeta mismo contesta a su pregunta. Echa un suspiro y reconoce que el mal es inmenso y que es muy difícil que el hombre lo venza. "Desgraciadamente" recoge el adverbio del primer verso: éste es otro poema que completa un círculo y 
nuevamente el sufrimiento se presenta como un círculo vicioso $\sin$ salida $\left({ }^{5}\right)$.

En resumen, para Vallejo el mal es inherente a la vida en cuanto está arraigado en la naturaleza humana y en cuanto existe en el universo una fuerza malévola que hace sufrir al hombre. Este concepto del mal como una fuerza malévola es el dominante en la poesía de Vallejo. A veces la ve, como los románticos, como una fuerza que le asesta golpes de desgracia al hombre; a veces, como Kalka, como una fuerza oscura y horrible que persigue al hombre como una pesadilla; a veces, como Camus, como una plaga que se adueña del universo. El mal constituye una de las grandes manifestaciones del absurdo y es uno de los temas principales de la poesía de Valle.jo.

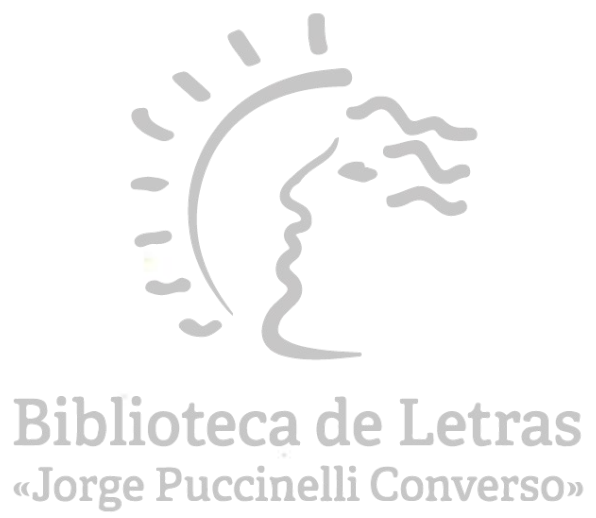

5. Este poema tiene también implicaciones positivas: el pocta parece sugerir la posibilidad de superar el mal a través de la solidaridad humana. Este aspecto del pensamiento de Vallejo es tema de otrol estudio, ya que éste se limita a examinar cómo el poeta concibe el mal. 